\title{
Does health check-up once in a year is worthy or not?
}

\author{
Prof. M. Karim Khan
}

Health checkup once in a year is a must in USA \& Japan after 50 years of age. In our country who are doing some jobs in Government \& non-government sector needs to do a checkup yearly as a part of ACR (annual confidential report). But sorry to mention that often not done very properly. Ideally not only the adult one but periodic medical checkup is beneficiary for any person at any age.

The routine physical, also known as general medical examination, periodic health evaluation, annual physical, comprehensive medical exam, general health check, preventive health examination, medical check-up, or simply medical, is a physical examination performed on an asymptomatic patient for medical screening purposes. These are normally performed by a medical doctor, family practice physician, or other primary care provider. This routine physical exam usually includes the HEENT evaluation. If necessary, the patient may be sent to a medical specialist for more detailed examinations. ${ }^{1}$

One of my teacher who was apparently healthy but on routine checkup he was found diabetic. My relative went for a routine checkup \& after doing an USG scan of abdomen, she found to have cholelithiasis. So routine checkup at any age once or twice in a year is important to diagnose any hidden disease condition earlier \& thus management becomes easier before developing any complications.

The general medical examination generally involves a medical history, a complete physical examination and sometimes laboratory tests. Some more advanced tests include ultrasound and mammography. If done for a group of people the routine physical is a form of screening, as the aim of the examination is to detect early signs of diseases to prevent them. ${ }^{2}$

Few studies in 2006 reveled that in addition to general physical examination \& routine test, if someone does periodic PAPS smear, Cholesterol screening, faecal occult blood test may get more benefit. ${ }^{3}$

To diagnose a disease condition there are three fundamental methods that we follow a) a meticulous history taking b) a complete physical examination c) some relevant laboratory examination which are rational \& cost effective.

Sometimes we do comprehensive or executive checkup. Comprehensive physical exams, also known as executive physicals, typically include laboratory tests, chest $\mathrm{x}$ rays, pulmonary function testing, audiograms, full body Computed Axial

Tomography (CAT) scanning, Electrocardiograms (EKGs), heart stress tests, vascular age tests, urinalysis, and mammograms or prostate exams depending on gender.

In our country as well as in other country pre-employment checkup is there. That also helps a lot to screen out any disease or disability. Premarital checkup specially some lab test like Hemoglobin $(\mathrm{Hb})$ electrophoresis, blood group estimation, decreases many disease condition of future, which are done in many countries routinely. Our government also trying to impose that before getting married. In Bangladesh there are a good number of people they are afraid to do any physical \& lab examination as they think this examination may disclose some unwanted undesirable disease condition like Hypertension, diabetes, heart disease, malignancy etc. But they do not often realize that early diagnosis \& prompt treatment of those diseases decreases morbidity \& increases life span

In conclusion we can say that routine medical checkup once or twice in a year is

1. Prof. M. Karim Khan

Professor of pediatrics \& Director of Hospital.

Community Based Medical College, Mymensingh.

Address of correspondence:

Email: mmukkhan@gmail.com

Mobile: +8801711350724 
always beneficiary. By doing that hidden diseases may be diagnosed earlier before developing any complications. Their management also become easier \& less costly. We all wishes to have a healthy, happy \& disease free life \& periodic health checkup helps us to achieve that goal.

\section{References:}

1. Schreiber, Mary L. Evidence-Based Practice. Neurovascular Assessment: An Essential Nursing Focus. MEDSURG Nursing (MEDSURG NURS). Jan/Feb 2016; 25(1): 55-57. ISSN 1092-0811

2. Raffle, Angela E. Muir Gray, JA. (2007) Screening: Evidence and practice. Oxford University Press. doi:10.1093/acprof: oso/9780199214495.001.0001. ISBN 9780-19-921449-5.

3. Boulware LE, Marinopoulos S, Phillips KA, et al. (February 2007). "Systematic review: the value of the periodic health evaluation". Ann. Intern. Med. 146 (4): 289-300. Doi:10.7326/0003-4819-146-4-20070220000008.PMID 17310053.

4. "Johns Hopkins Executive Health Program". Archived from the original on 2009-12-24. Retrieved 2009-07-16. 